\title{
Effect of Extremely Low Frequency Magnetic Fields on Gene Expression in Human Mammary Epithelial MCF10A Cells
}

\author{
Mi-Na Hong ${ }^{1,5,+} \cdot$ Hyung-Chul Lee ${ }^{1,5,+} \cdot$ Bong Cho Kim ${ }^{1} \cdot$ Yun-Sil Lee ${ }^{2} \cdot$ \\ Yoon-Myung Gimm ${ }^{3} \cdot$ Sung-Ho Myung ${ }^{4} \cdot$ Jae-Seon Lee $^{1}$
}

\begin{abstract}
The effects of extremely low frequency magnetic fields (ELF-MFs) on physiological processes at the cellular level remain unclear despite a number of studies. To investigate the effects of ELF-MFs on gene expression, we exposed human mammary epithelial MCF10A cells to fields of $1 \mathrm{mT}$ magnetic flux density at $60 \mathrm{~Hz}$ for 4 and $16 \mathrm{~h}$ and measured the transcriptional responses of 24,000 genes using Illumina microarrays. In three independent experiments, we found no statistically significant alteration of expression levels for any of the genes assayed using a cutoff value of 1.2-fold. To confirm this result, we selected six genes with trends suggesting possible expression level changes, although these trends were not statistically significant, and investigated their expression levels further using a semiquantitative reverse-transcription polymerase chain reaction. In three independent experiments, we did not find any alterations in the expression levels of these genes. From these results, we conclude that ELF-MFs do not affect gene expression profiles under our exposure conditions.
\end{abstract}

Key words: Biological Effect, ELF-MF, Gene Expression, MCF10A Cells, Microarray.

\section{I . Introduction}

Extremely low frequency magnetic fields (ELF-MFs) ranging from 3 to $300 \mathrm{~Hz}$ are generated by high-voltage electrical power transmission lines and secondary distribution lines. Concerns are frequently raised among the general public regarding possible adverse health effects associated with ELF-MF exposure. Over the last three decades, many research groups have conducted studies to determine the effects of ELF-MFs on biological systems. Epidemiological studies reported a link between the risks of various cancers, particularly childhood leukemia, and ELF-MF exposure [1]. Other studies suggested that exposure to magnetic fields (MFs) due to regular proximity to electrical power lines or occupational demands increased the risks of cardiovascular disease and Alzheimer's disease [2], [3]. In vitro studies have shown that ELF-MF could influence cell proliferation and cytoskeletal organization, and could induce DNA damage through the action of free radical species [4] [6]. Martínez et al. reported that ELF-MF could stimulate proliferative activity in neuronal cells by triggering MAPKERK1/2 signaling [7]. It has been also reported that electromagnetic fields (EMF) transiently influence the transcript level of genes related to apoptosis and the cell cycle [8], [9]. However, in vitro studies failed to demonstrate any biological effects of ELF-MFs [10] [13]. Magnetic fields have no significant effects on levels of stress proteins, cytoskeleton proteins, and the proliferation of astroglial cells [14]. ELF-MF has no effect on intracellular ROS level, SOD activity, and the ratio of GSH/GSSG in MCF10A cells [15]. Because of these apparently conflicting results, the biological effects of ELF-MF exposure remain an open question.

Although the radical pair mechanism has been suggested as a candidate, a fundamental mechanism of interaction between ELF-MFs and biological systems has not been demonstrated [10]. If ELF-MF exposure could

\footnotetext{
Manuscript received September 28, 2012 ; Revised October 30, 2012 ; Accepted December 4, 2012. (ID No. 20120928-020J)

${ }^{\dagger}$ These authors contributed equally to this work.

${ }^{1}$ Division of Radiation Cancer Research, Korea Institute of Radiological \& Medical Sciences, Seoul, Korea.

${ }^{2}$ College of Pharmacy \& Division of Life Science and Pharmaceuticals, Ewha Womans University, Seoul, Korea.

${ }^{3}$ School of Electronics and Electrical Engineering, Dankook University, Yongin, Korea.

${ }^{4}$ Smart Grid Research Division, Korea Electrotechnology Research Institute, Changwon, Korea.

${ }^{5}$ School of Life Sciences and Biotechnology, Korea University, Seoul, Korea.

Corresponding Author : Jae-Seon Lee (e-mail : jaeslee@kirams.re.kr)
}

This is an Open-Access article distributed under the terms of the Creative Commons Attribution Non-Commercial License (http://creativecommons.org/licenses/ by-nc/3.0) which permits unrestricted non-commercial use, distribution, and reproduction in any medium, provided the original work is properly cited. 
modulate cellular processes such as proliferation, apoptosis, and differentiation, it might be mediated through alterations of gene expression. Altered gene expression could also serve as a useful biomarker for MF exposure. Most studies examining the response of expression levels to MF exposure have only looked at small numbers of genes [11] [13]. High-throughput transcriptomics and proteomics could identify putative molecular targets and the possible molecular mechanisms of EMF exposure where previous studies of small numbers of genes have failed to do so [16], [17]. A microarray containing the entire human transcriptome permits a much more thorough investigation of potential changes in transcription levels compared with classical methodologies [18].

The aim of this study was to examine alterations in the expression profile of the human genome following ELF-MF exposure. We investigated the transcriptional response of MCF10A human breast epithelial cells exposed to $1 \mathrm{mT}$ ELF-MFs at $60 \mathrm{~Hz}$ using microarrays containing 24,000 human genes.

\section{Materials and Method}

\section{2-1 Cell Culture}

A MCF10A human breast epithelial cell line was purchased from the American Type Culture Collection (ATCC) (Manassas, USA). The cells were routinely maintained in a 1:1 mix of DMEM and Ham's F12 media (Invitrogen, Carlsbad, USA) supplemented with $5 \%$ horse serum (Invitrogen), $100 \mu \mathrm{g} / \mathrm{ml}$ of streptomycin and $100 \mathrm{U} / \mathrm{ml}$ of penicillin (WelGENE, Daegu, Korea), $11.2 \mu \mathrm{g} / \mathrm{ml}$ insulin (Sigma, St. Louis, USA), $21 \mathrm{ng} / \mathrm{ml}$ epidermal growth factor (Peprotech, Rocky Hill, USA), $50 \mathrm{ng} / \mathrm{ml}$ cholera toxin (Sigma), and $525 \mathrm{ng} / \mathrm{ml}$ Hydrocortisone (Sigma) in a humidified atmosphere containing $5 \% \mathrm{CO}_{2}$

\section{2-2 Exposure System and Exposure to ELF MF}

The MF generation equipment was designed and constructed by Korea Electrotechnology Research Institute as described in Hong et al. [15]. The field generator consists of four square-shaped coils and one cage with three testing floors (a top, middle, and bottom floor) as shown in Fig. 1(a). The voltage fluctuation rate and harmonic rate of power quality using power amplifier was under $1 \%$. Fixing the magnetic field at the center of the middle floor was $1 \mathrm{mT}$. The spatial variation of magnetic field was under $3 \%$. This strongly demonstrates that the field generator is good for a small-sized in vitro study. The total ELF-MF exposure system, in-
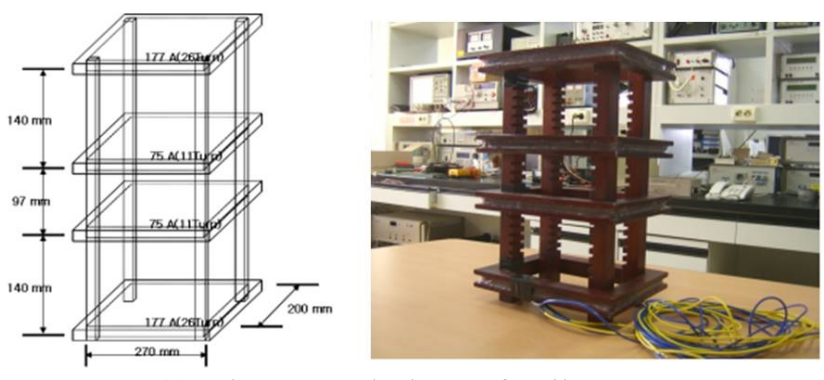

(a) Diagram and photo of coil system

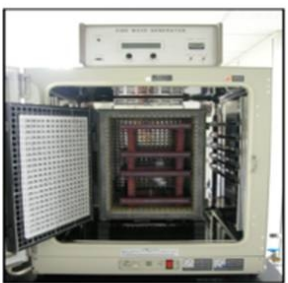

(b) Total in vitro ELF-MF exposure system, including cell culture incubator

Fig. 1. Configuration of coil part in exposure system.

cluding the cell culture incubator, is demonstrated in Fig. 1(b). The temperature of the incubator was maintained at $37 \pm 0.3{ }^{\circ} \mathrm{C}$ during the exposure period using a water-jet cooling system. The magnetic field shielding system using ferrite material was adopted to shield the strong magnetic field in the outer ELF-MF exposure system. We used two exposure systems (a sham exposure system and ELF-MF exposure system) for this study. The ELF-MF exposure system was warmed up for $15 \mathrm{~min}$ to equilibrate it prior to exposure. Cells in the $100 \mathrm{~mm}$ Petri dish were exposed to $60 \mathrm{~Hz}$ at $1 \mathrm{mT}$ intensity for $4 \mathrm{~h}$ or $16 \mathrm{~h}$. For the sham exposure, cells were kept in the ELF-MF exposure system without MF generation. The temperature was maintained at $37 \pm 0.3$ ${ }^{\circ} \mathrm{C}$ throughout the exposure period in both the shamexposed and ELF-MF-exposed groups.

\section{2-3 RNA Preparation}

Total RNA was extracted using Trizol (Invitrogen Life Technologies, Carlsbad, USA) and was purified using RNeasy columns (Qiagen, Valencia, USA) according to the manufacturers' protocol. After DNase digestion and clean-up procedures, RNA samples were quantified, aliquoted, and stored at $-80{ }^{\circ} \mathrm{C}$ until being utilized. For quality control, RNA purity and integrity were evaluated by denaturing gel electrophoresis, and analyzed OD 260/280 ratio using Agilent 2100 Bioanalyzer (Agilent Technologies, Palo Alto, USA).

\section{2-4 Microarray Analysis}

Total RNA was amplified using the Ambion Illumina 
RNA amplification kit (Ambion, Austin, USA) to yield biotinylated cRNA according to the manufacturer's instructions. Briefly, $550 \mathrm{ng}$ of total RNA was reversetranscribed to cDNA using a T7 oligo (dT) primer. Second-strand cDNA was synthesized, in vitro transcribed, and labeled with biotin-NTP. After purification, cDNA was quantified using the ND-1000 Spectrophotometer (NanoDrop, Wilmington, USA) and $750 \mathrm{ng}$ of labeled cDNA samples were hybridized to each HumanRef-8 Expression Beadchip (Illumina Inc., San Diego, USA) containing more than 24,000 oligonucleotide probes for $16 \sim 18 \mathrm{~h}$ at $58{ }^{\circ} \mathrm{C}$, according to the manufacturer's instructions. Detection of the array signal was accomplished by using Amersham fluorolink streptavidin-Cy3 (GE Healthcare Bio-Sciences, Little Chalfont, UK) following the bead array manual. Arrays were scanned with an Illumina bead array reader confocal scanner (Illumina Inc., San Diego, USA). Array data export processing and analysis is performed using Illumina Genome Studio v2009.2 (Gene Expression Module v1.5.4).

\section{2-5 Raw Data Preparation and Statistic Analysis}

The quality of hybridization and overall chip performance were monitored through visual inspection of both internal quality control checks and the raw scanned data. Raw data were extracted using the software provided by the manufacturer (Illumina GenomeStudio v2009.2; Gene Expression Module v1.5.4). Array data were filtered by detection $p$-value $<0.05$ (similar to signal to noise) in at least $50 \%$ of the samples (we applied a filtering criterion for data analysis; a higher signal value was required to obtain a detection $p$-value $<0.05$ ). The selected gene signal value was transformed with a logarithm and normalized by applying the quantile method. The statistical significance of the expression data was determined using the Paired $t$-test in which the null hypothesis was that no difference exists between the mean of the groups used in the data pool. False discovery rate (FDR) was controlled for by adjusting the $p$-value using the Benjamini-Hochberg algorithm. Goontology analysis for probe list was performed using PANTHER (http://www.pantherdb.org/panther/ontologies. jsp), using text files containing a Gene ID list, and the accession number of Illumina probe ID. Gene Set Enrichment Analysis (GSEA) was performed whether a priori defined set of genes showed a differential pattern between both biological process and molecular function states. One-tail Fisher Exact was adopted to measure the gene enrichment in annotation terms. Hierarchical clustering was performed using complete linkage with a Euclidian metric. GenomeStudio v2009.2 software was used for quantification and image analysis of mRNA data. R scripts were used for all other analytical process.

\section{2-6 Semi-Quantitative Reverse-Transcriptase PCR}

Total RNA was used as a template for cDNA synthesis with M-MLV RT utilizing the Superscript TM III reverse transcriptase kits (Invitrogen Life Technologies, Carlsbad, USA). Subsequently, PCR was performed by $22 \sim 28$ cycles. The forward and reverse primer sequence are as follows: CCNH forward 5'-CTG ACG CCA ACC GCA AAT TC-3', reverse 5'-CTG GCT TAA ACA CCG AAC AGA A-3'; F3 forward 5'-GTG ATT CCC TCC CGA ACA GTT-3', reverse 5'-CTG GCC CAT ACA CTC TAC CG-3'; ACTR3 forward 5'-GGA GTC AGC AAA AGT GGG TGA-3', reverse 5'-GTC TTC AGG TTC TGC CCT TAA AT-3'; IFIT3 forward 5'-TCA GAA GTC TAG TCA CTT GGG G-3', reverse 5'-ACA CCT TCG CCC TTT CAT TTC-3'; PRKAR1A forward 5'-GAT GGG CAG AAG ATT GTG GTG-3', reverse 5'-GGA CGA TTC ATC AGT AGT GCA A-3'; NAE1 forward 5'-TTC ACT ACG CTT AGC AGA TGT CC-3', reverse 5'-ATG GAG TAT GAC TGT GGT CCT T-3'; and GAPDH forward 5'-TCA GAA GTC TAG TCA CTT GGG G-3', reverse 5'-ACA CCT TCG CCC TTT CAT TTC-3'. The primers were obtained from the Bioneer Corporation (Daejeon, Korea). The final RT-PCR products were electrophoresed on 2.0 $\%$ agarose gel, stained with $0.5 \mathrm{~g} / \mathrm{ml}$ ethidium bromide solution, and visualized on a UV transilluminator (BioRad Laboratories, Hercules, CA). In this system, PCR products were quantified using Gel-Doc (Bio-Rad Laboratories, Hercules, CA).

\section{2-7 Statistical Analysis}

All values are expressed as mean $\pm \mathrm{SD}$. The student's $t$-test was performed with Origin 6.0 (Origin Lab, Northampton, USA). A $p$-value less than 0.05 was considered significant.

\section{Results}

\section{3-1 High-Throughput Gene Expression Profile of ELF- MF-Exposed MCF10A Cells}

As outlined in Fig. 2, MCF10A cells were exposed to $1 \mathrm{mT}$ ELF-MFs at $60 \mathrm{~Hz}$ for 4 and $16 \mathrm{~h}$. The cells showed no microscopically detectable changes in cellular morphology compared with sham-exposed cells (Fig. 3). To identify genes that were affected by ELFMF exposure, we performed three independent replicate microarray analyses for sham- and ELF-MF-exposed MCF 

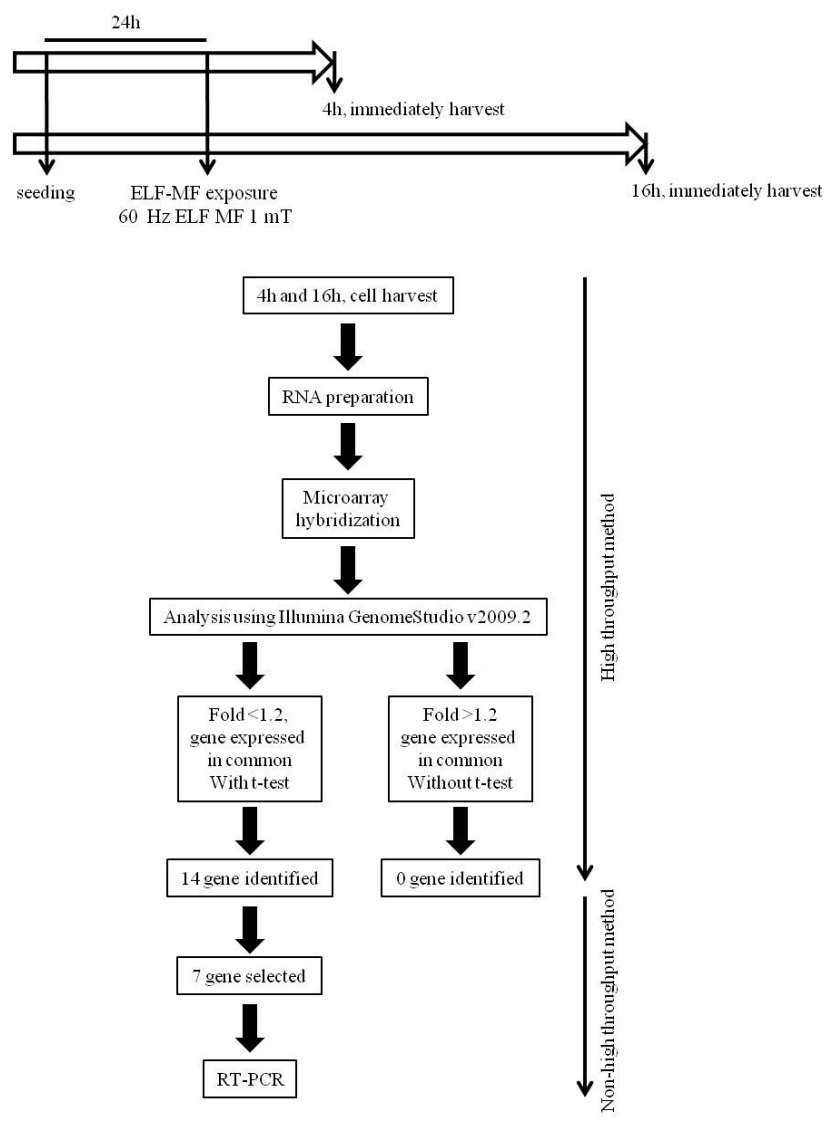

Fig. 2. Experimental protocol.

4h

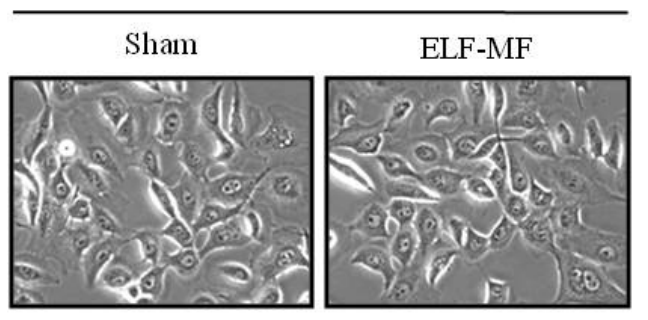

$16 \mathrm{~h}$

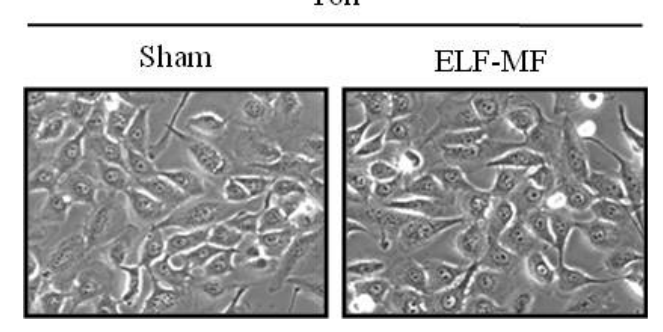

Fig. 3. Morphology of MCF10A cells after $1 \mathrm{mT}$ ELF-MF exposure at $60 \mathrm{~Hz}$ for 4 and $16 \mathrm{~h}$. Cellular morphology was examined using phase-contrast microscopy (100×magnification).

$10 \mathrm{~A}$ cells after $4 \mathrm{~h}$ and $16 \mathrm{~h}$ exposures, including ELFMF exposure, sample preparation, and hybridization, in order to obtain a reproducible list of altered genes. The- refore, we ran a total of 12 microarray experiments and determined the statistical significance of the expression data using paired $t$-tests. Initially, we chose a change in the expression level of 1.5 -fold, a commonly used cutoff value in microarray analysis, as our cutoff value. However, we did not find any genes with statistically significant 1.5 -fold alterations in the expression level. So we performed the analysis using a cutoff value of 1.2fold and still found no statistically significant changes in the expression level of any gene (Fig. 2).

\section{3-2 Validation of High-Throughput Results Using RT- PCR}

In order to reduce the likelihood that our failure to find any impact on gene expression from ELF-MF exposure was due to statistical limitations, we conducted further analysis of a small number of genes using semi-quantitative RT-PCR (sqRT-PCR). Using relaxed criteria to identify differentially expressed genes, we selected 14 genes that exhibited statistically non-significant trends for altered expression levels (|average fold change $>1.2$ ) both at the 4 and at $16 \mathrm{~h}$ of ELF-MF exposure (Table 1). We randomly selected six of the fourteen genes in Table 1: coagulation factor III (F3), interferon-induced protein with tetratricopeptide repeats 3 (IFIT3), ARP3 actin-related protein 3 homology (ACTR3), cyclin $\mathrm{H}(\mathrm{CCNH})$, protein kinase, cAMP-dependent, regulatory, type I, alpha (PRKAR1A), and NEDD8 activating enzyme E1 subunit 1 (NAE1).

We preformed three replicate sqRT-PCR experiments with independent ELF-MF exposures and RNA extractions (Fig. 4). We used the expression level of GAPDH as a baseline to quantify and normalize the PCR signal intensities of the selected genes. Fig. 4 shows the mean \pm standard deviation $(\mathrm{M} \pm \mathrm{SD})$ of each mRNA level in the ELF-MF-exposed cells relative to that of the sham-exposed cells. The sqRT-PCR results confirmed that the expression levels of the six selected genes were not altered by EMF-MF exposure.

\section{Discussion}

We conducted microarray analysis to elucidate the effects of ELF-MF exposure on gene expression. Using high-throughput analysis, we found that genome-wide expression levels in MCF10A human breast epithelial cells were not changed by exposure to ELF-MFs. To confirm these results, we performed sqRT-PCR on six genes selected from the microarray analysis that exhibited statistically non-significant trends for expression changes; the follow-up results confirmed those of the 
Table 1. List of genes which showed common alterations in their expressions at both $4 \mathrm{~h}$ and $16 \mathrm{~h}$ without statistical significance after ELF-MF exposure ( $\mid$ average fold change $\mid>1.2$ ).

\begin{tabular}{|c|c|c|}
\hline Accession & Definition & Function \\
\hline NM_001239.2 & Cyclin $\mathrm{H}(\mathrm{CCNH})^{*}$ & $\begin{array}{l}\text { Select regulatory molecule -> } \\
\text { Kinase modulator }\end{array}$ \\
\hline NM_005721.3 & ARP3 actin-related protein 3 homolog (y east) (ACTR3)* & $\begin{array}{l}\text { Cytoskeletal protein -> Actin family } \\
\text { cytoskeletal protein }\end{array}$ \\
\hline NM_002734.3 & $\begin{array}{l}\text { Protein kinase, cAMP-dependent, regulatory, type I, alpha } \\
\text { (tissue specific extinguisher 1) (PRKAR1A)* }\end{array}$ & $\begin{array}{l}\text { Select regulatory molecule -> } \\
\text { Kinase modulator }\end{array}$ \\
\hline NM_001993.2 & Coagulation factor III (thromb oplastin, tissue factor) $(\mathrm{F} 3)^{*}$ & Receptor -> Cytokinereceptor \\
\hline NM_001549.2 & $\begin{array}{l}\text { Interferon-induced protein with tetratricopeptide repeats } 3 \\
\text { (IFIT3)* }\end{array}$ & Miscellaneous function \\
\hline NM_001018160.1 & NEDD8 activating enzyme E1 subunit 1 (NAE1)* & Ligase $->$ Other ligase \\
\hline NM_006947.3 & Signal recognition paticle $72 \mathrm{kDa}$ (SRP72) & Molecular function unclassified \\
\hline NM_138428.3 & Chromosome 1 open reading frame 212 (C1 orf212) & Molecular function unclassified \\
\hline NM_006527.2 & Stem-loop binding protein (SLBP) & Nucleic acid binding \\
\hline NM_000572.2 & Interleukin 10 (IL10) & Cytokine->Interleukin \\
\hline NM_022873.2 & Interferon, alpha-inducible protein 6 (IFI6) & Molecular function unclassified \\
\hline NM_001024682.1 & Hypothetical protein LOC283755 (LOC283755) & Oxidoreductase $->$ Oxidase \\
\hline NM_030881.2 & DEAD (Asp-Glu-Ala-Asp) box polypeptide 17 (DDX17) & $\begin{array}{c}\text { Nucleic acid binding }->\text { Helicase }-> \\
\text { RNA helicase }\end{array}$ \\
\hline NM_001080484.1 & KIAA1751 (KIAA1751) & \\
\hline
\end{tabular}

* Indicates genes selected for sqRT-PCR analysis.

microarray experiments. Therefore, we conclude that 1 $\mathrm{mT}$ EMF-MF exposures for 4 and $16 \mathrm{~h}$ do not alter gene expression profiles in MCF10A human mammary epithelial cells.

Previous studies reported that ELF-MF exposure could affect transcription levels in vitro of several immediate-response genes [8], [19] [21]. These studies, however, only looked at a few genes and their results require further confirmation before firm conclusions can be drawn. Recent technical advances now make it possible to simultaneously monitor the expression of thousands of genes across entire genomes. Such high-throughput technology has the potential to resolve the uncertainties about whether ELF-MF exposure is harmful to biological systems. Additionally, it could help to elucidate the biological mechanisms and pathways affected by MFs [1]. Several groups have conducted analyses using high-throughput technologies to determine the biological effects of ELF-MF exposure. Loberg et al. [22] found, using arrays containing cDNAs, that MF exposure did not affect the expression of 588 cancer-rela- ted genes. They performed three independent exposures of normal (HME) and transformed (HBL-100) human mammary epithelial cells and human promyelocytic leukemia (HL60) cells to 0.01 or $1 \mathrm{mT}$ MFs at $60 \mathrm{~Hz}$ for $24 \mathrm{~h}$. In the same year, Balcer-Kubiczek et al. [23] exposed $960 \mathrm{cDNA}$ clones to $2 \mathrm{mT}$ MFs at $60 \mathrm{~Hz}$ for $24 \mathrm{~h}$ and found no effect on the expression levels of the selected genes. Luceri et al. [18] exposed human and yeast cells to ELF-MFs and measured expression levels with microarrays containing 13,971 and 6,212 oligonucleotide probes. Their results suggested that ELF-MFs did not affect gene expression in either eukaryotic system. Henderson et al. [1] used oligonucleotide microarrays containing up to 30,000 genes to investigate transcriptional responses to various intensities of MF exposure in human primary vascular endothelial cells. They found no reproducible effects of MF exposure on the expression of any of the genes.

In contrast to the negative results mentioned above, Zhao et al. [24] used rat oligo osteogenesis microarrays to show that Bmp1 (bone morphogenic protein) and 


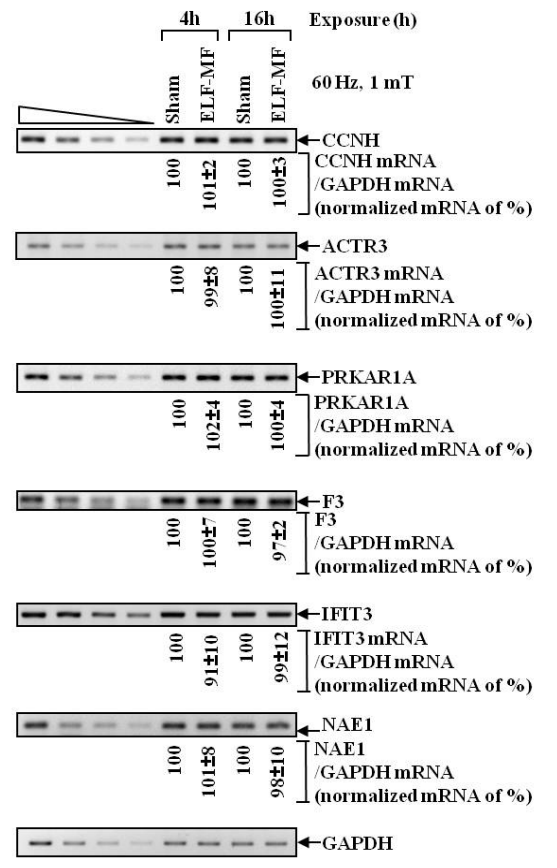

(a)

Fig. 4. SqRT-PCR analysis and densitometric quantitation of ELF-MF-exposed MCF10A cells. Specific primers for the CCNH, ACTR3, PRKAR1A, F3, IFIT3, and NAE1 genes were used for PCR. The mRNA level of each gene was normalized relative to that of GAPDH. Representative PCR data are shown from three independent experiments. The numbers below the PCR data are the relative values of the sham-exposed samples expressed as the mean \pm SD from three independent experiments.

Bmp7 mRNAs were up-regulated, whereas Egf (epidermal growth factor) and Egfr (epidermal growth factor receptor) mRNAs were down-regulated, in Sprague Dawley rat bone-marrow mesenchymal stem cells exposed to EMFs $(15 \mathrm{~Hz}, 1 \mathrm{mT}, 5 \mathrm{~h} / \mathrm{d})$ for 2 days. They reported that these altered genes could be involved in diverse biological processes such as skeletal development, bonemineral metabolism, cell growth and differentiation, cell adhesion, and so forth Two other groups conducted microarray analyses of cells exposed to ELF electrical fields (EFs), instead of ELF-MFs, and demonstrated a modified expression of Bmp, Dickkopf-related protein 1 (DKK1), thioredoxin reductase 1 (TXNRD1), cyclic AMPdependent transcription factor 3 (ATF3), membrane metallo-endopeptidase (MME), and microtubule-actin crosslinking factor 1 (MACF1) in human epidermal cells [19], [25].

In our study, we tried to identify up- or downregulated genes using a cutoff value of 1.2-fold. None of these genes, however, was significantly $(p<0.05)$ upor down-regulated when the results of all three independent experiments were considered together. Therefore, we did not obtain conclusive evidence of altered gene expression following ELF-MF exposure. These results suggest that observations of ELF-MF-induced changes in expression levels based on single experiments might be spurious and should be confirmed with replicate experiments; this is consistent with the conclusions of previous reports published by Loberg et al. [22] and Henderson et al. [1].

Microarray technology has advanced tremendously in recent years; however, the potential for misleading results remains. Microarrays have the power to evaluate the expression of many genes simultaneously and without proper experimental design, it is sometimes impossible to distinguish important results from random fluctuations. Because it is designed to detect small changes in gene expression profiles, microarray technology is sensitive enough to reflect subtle alterations in sample preparation procedures, environmental conditions, or experimental procedures [18]. Therefore, we suggest that microarray experiments should be conducted with at least three-fold replication to establish the reproducibility of their results. Additionally, the results of microarray experiments should be validated using reverse transcription polymerase chain reaction (RT-PCR) whenever possible. So far, only a few research groups have reported results from high-throughput analyses of the effects of ELF-MF exposure on transcription; more studies will be required to conclusively determine the biological effects of ELF-MF exposure.

This work was supported by the Power Generation \& Electricity Delivery of the Korea Institute of Energy Technology Evaluation and Planning (KETEP) grant funded by the Korean government's Ministry of Knowledge Economy (No. 2009101030003E).

\section{References}

[1] B. Henderson, M. Kind, G. Boeck, A. Helmberg, and G. Wick, "Gene expression profiling of human 
endothelial cells exposed to $50-\mathrm{Hz}$ magnetic fields fails to produce regulated candidate genes," Cell Stress Chaperones, vol. 11, no. 3, pp. 227-232, 2006.

[2] Z. Davanipour, C. C. Tseng, P. J. Lee, and E. Sobel, "A case-control study of occupational magnetic field exposure and Alzheimer's disease: results from the California Alzheimer's Disease Diagnosis and Treatment Centers," BMC Neurol, vol. 7, pp. 13-23, 2007.

[3] D. A. Savitz, D. Liao, A. Sastre, R. C. Kleckner, and R. Kavet, "Magnetic field exposure and cardiovascular disease mortality among electric utility workers," Am. J. Epidemiol., vol. 149, no. 2, pp. 135142, 1999.

[4] R. Polaniak, R. J. Bułdak, M. Karoń, K. Birkner, M. Kukla, K. Zwirska-Korczala, and E. Birkner, "Influence of an extremely low frequency magnetic field (ELF-EMF) on antioxidative vitamin $\mathrm{E}$ properties in AT478 murine squamous cell carcinoma culture in vitro," Int. J. Toxicol., vol. 29, no. 2, pp. 221-230, 2010.

[5] M. Sulpizio, S. Falone, F. Amicarelli, M. Marchisio, F. Di Giuseppe, E. Eleuterio, C. Di Ilio, and S. Angelucci, "Molecular basis underlying the biological effects elicited by extremely low-frequency magnetic field (ELF MF) on neuroblastoma cells," J. Cell Biochem., vol. 112, no. 12, pp. 3797-3806, 2011.

[6] F. I. Wolf, A. Torsello, B. Tedesco, S. Fasanella, A. Boninsegna, M. D'Ascenzo, C. Grassi, G. B. Azzena, and A. Cittadini, "50-Hz extremely low frequency electromagnetic fields enhance cell proliferation and DNA damage: possible involvement of a redox mechanism," Biochim. Biophys. Acta, vol. 1743, no. 1-2, pp. 120-129, 2005.

[7] M. A. Martínez, A. Úbeda, M. A. Cid, and M. Á. Trillo, "The proliferative response of NB69 human neuroblastoma cells to a $50 \mathrm{~Hz}$ magnetic field is mediated by ERK1/2 signaling," Cell Physiol. Biochem, vol. 29, no. 5-6, pp. 675-686, 2012.

[8] E. Gottwald, W. Sontag, B. Lahni, and K. F. Weibezahn, "Expression of HSP72 after ELF-EMF exposure in three cell lines," Bioelectromagnetics, vol. 28, pp. 509-518, 2007.

[9] T. Nikolova, J. Czyz, A. Rolletschek, P. Blyszczuk, J. Fuchs, G. Jovtchev, J. Schuderer, N. Kuster, and A. M. Wobus, "Electromagnetic fields affect transcript levels of apoptosis-related genes in embryonic stem cell-derived neural progenitor cells," FASEB J., vol. 19, no. 12, pp. 1686-1688, 2005.

[10] S. Burdak-Rothkamm, K. Rothkamm, M. Folkard, G. Patel, P. Hone, D. Lloyd, L. Ainsbury, and K. M. Prise, "DNA and chromosomal damage in response to intermittent extremely low-frequency mag- netic fields," Mutat. Res., vol. 672, no. 2, pp. 8289, 2009.

[11] L. A. Coulton, P. A. Harris, A. T. Barker, and A. G. Pockley, "Effect of $50 \mathrm{~Hz}$ electromagnetic fields on the induction of heat-shock protein gene expression in human leukocytes," Radiat. Res., vol. 161, no. 14, pp. 430-434, 2004.

[12] G. P. Jahreis, P. G. Johnson, Y. L. Zhao, and S. W. Hui, "Absence of $60-\mathrm{Hz}, 0.1-\mathrm{mT}$ magnetic field-induced changes in oncogene transcription rates or levels in CEM-CM3 cells," Biochim. Biophys. Acta, vol. 1443, no. 3, pp. 334-342, 1998.

[13] C. A. Morehouse, R. D. Owen, "Exposure to lowfrequency electromagnetic fields does not alter HSP70 expression or HSF-HSE binding in HL60 cells," Radiat. Res., vol. 153, no. 5, pp. 658-662, 2000.

[14] G. Bodega, I. Forcada, I. Suárez, and B. Fernández, "Acute and chronic effects of exposure to a 1-mT magnetic field on the cytoskeleton, stress proteins, and proliferation of astroglial cells in culture," Environ. Res., vol. 98, no. 3, pp. 355-362, 2005.

[15] M. N. Hong, N. K. Han, H. C. Lee, Y. K. Ko, S. G. Chi, Y. S. Lee, Y. M. Gimm, S. H. Myung, and J. S. Lee, "Extremely low frequency magnetic fields do not elicit oxidative stress in MCF10A cells," J. Radiat. Res., vol. 53, no. 1, pp. 79-86, 2012.

[16] K. B. Kim, H. O. Byun, N. K. Han, Y. G. Ko, H. D. Choi, N. Kim, J. K. Pack, and J. S. Lee, "Twodimensional electrophoretic analysis of radio-frequency radiation-exposed MCF7 breast cancer cells," J. Radiat. Res., vol. 51, no. 2, pp. 205-213, 2010.

[17] D. Leszczynski, M. L. Meltz, "Questions and answers concerning applicability of proteomics and transcriptomics in EMF research," Proteomics, vol. 6, no. 17, pp. 4674-4677, 2006.

[18] C. Luceri, C. De Filippo, L. Giovannelli, M. Blangiardo, D. Cavalieri, F. Aglietti, M. Pampaloni, D. Andreuccetti, L. Pieri, F. Bambi, A. Biggeri, and P. Dolara, "Extremely low-frequency electromagnetic fields do not affect DNA damage and gene expression profiles of yeast and human lymphocytes," Radiat. Res., vol. 164, no. 3, pp. 277-285, 2005.

[19] J. F. Collard, B. Mertens, and M. Hinsenkamp, "In vitro study of the effects of ELF electric fields on gene expression in human epidermal cells," Bioelectromagnetics, vol. 32, no. 1, pp. 28-36, 2011.

[20] R. Goodman, Y. Chizmadzhev, and A. Shirley-Henderson, "Electromagnetic fields and cells," J. Cell Biochem., vol. 51, no. 4, pp. 436-441, 1993.

[21] J. L. Phillips, W. Haggren, W. J. Thomas, T. Ishida-Jones, and W. R. Adey, "Magnetic field-induced changes in specific gene transcription," Biochim. 
Biophys. Acta., vol. 1132, no. 2, pp. 140-144, 1992.

[22] L. I. Loberg, W. R. Engdahl, J. R. Gauger, and D. L. McCormick, "Expression of cancer-related genes in human cells exposed to $60 \mathrm{~Hz}$ magnetic fields," Radiat. Res., vol. 153, no. 5, pp. 679-684, 2000.

[23] E. K. Balcer-Kubiczek, G. H. Harrison, C. C. Davis, M. L. Haas, and B. H. Koffman, "Expression analysis of human HL60 cells exposed to $60 \mathrm{~Hz}$ square- or sine-wave magnetic fields," Radiat. Res.,

\section{Mi-Na Hong}

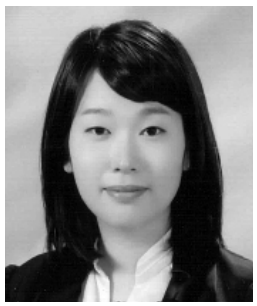

received the B.S degree in biological science from SookMyung Women's University, Seoul, Republic of Korea in 2008 and the M.S. degree in molecular biology from Korea University, Seoul, Republic of Korea in 2011. She is currently working toward a Ph.D. degree in molecular biology at Korea University. Her research interests include that effect of ELF-MF on cell proliferation and gene expression. vol. 153, no. 2, pp. 670-678, 2000.

[24] Y. L. Zhao, J. C. Yang, and Y. H. Zhang, "Effects of magnetic fields on intracellular calcium oscillations," Conf. Proc. IEEE Eng. Med. Biol. Soc., vol. 2008, pp. 2124-2127, 2008.

[25] M. Hinsenkamp, J. F. Collard, "Bone morphogenic protein-mRNA upregulation after exposure to low frequency electric field," Int. Orthop., vol. 35, no. 10, pp. 1577-1581, 2011.
Bong Cho Kim

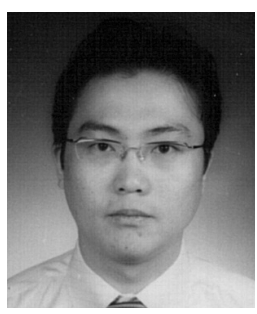

received the B.S. degree in biological science from Dankook University, and the M.S. and Ph.D. degrees in College of Medicine from Seoul National University. He studied in stem cell field at Department of Biochemistry and Molecular Biology from Ajou University School of Medicine. $\mathrm{He}$ is currently studying in Korea Institute of Radiological \& Medical Sciences as a postdoctoral fellow with Jae-Seon Lee, Ph.D. His research interests include the effects of stress signals on cellular physio$\log$.

\section{Hyung-Chul Lee}

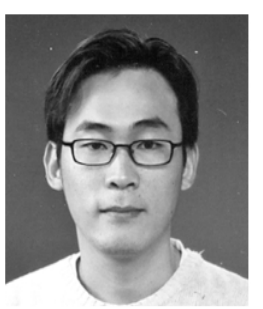

received the B.S. and M.S. degree in molecular cellular biology from Pusan National University, Pusan, Republic of Korea in 2004 and 2006, respectively. He is currently working toward a Ph.D. degree in molecular cellular biology at Korea University. His research interests include that ELF-MF effect cellular phenotype.
Yun-Sil Lee

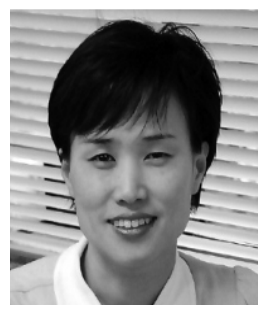

received the B.S., M.S. and Ph.D. degrees in College of Pharmacy from Ewha Womans University, Seoul, Republic of Korea in 1985, 1988 and 1994, respectively. She is currently working in College of Pharmacy at Ewha Womans University as an associate professor. Her research interests include that effect of ELF-MF and $\mathrm{RF}$ on cellular and animal study fields. 


\section{Yoon-Myung Gimm}

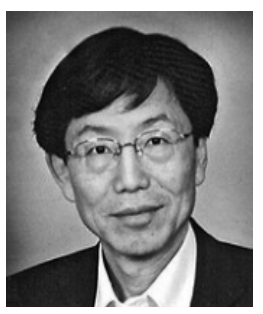

received the B.E. degree in electronics engineering from the Seoul National University, Seoul, Korea, in 1975, and the M.S. and $\mathrm{Ph} . \mathrm{D}$. degrees in electrical and electronics engineering from Korea Advanced Insititute of Science and Technology (KAIST) in 1977 and 1990, respectively. Since 1980, he has been with the department of electronics engineering, Dankook University, where he is now a professor in the school of electronics and electrical engineering. He is also a CEO of EMF Safety Inc., since 2000. His research interests are the electromagnetic field measurements related with the biological effect and human safety.

\section{Sung-Ho Myung}

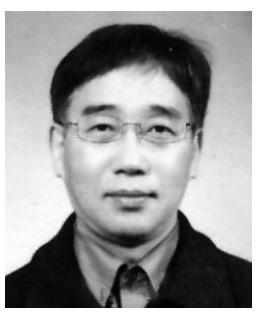

received his Ph.D. degree in electrical engineering from Seoul National University, Koreain 1996. Since 1985, he has been at KERI as a principal researcher. Currently, he is an executive director in the Advanced Power Grid Research Division. His areas of interest are assessment of the EMF effects of electric power facilities, EMF mitigation design of transmission line. From 1998 2013, he was a project manager-in-charge of the EMF National Project.

\section{Jae-Seon Lee}

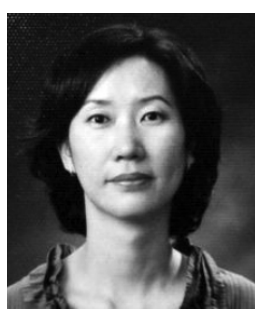

received her Ph.D. degree in Korea University in 1992. She studied as a postdoctoral fellow in University of Wisconsin at Madison, USA in 1993 1994. Currently, she is working in Korea Institute of Radiological \& Medical Sciences as a principal investigator. Recent research interest is focus on the biological effects of non-ionizing and ionizing radia radiations in vitro and in vivo. 